\title{
Understanding the regulatory and transcriptional complexity of the genome through structure
}

\author{
Tim R. Mercer and John S. Mattick ${ }^{1}$ \\ Garvan Institute of Medical Research, Sydney, New South Wales, Australia 2010
}

\begin{abstract}
An expansive functionality and complexity has been ascribed to the majority of the human genome that was unanticipated at the outset of the draft sequence and assembly a decade ago. We are now faced with the challenge of integrating and interpreting this complexity in order to achieve a coherent view of genome biology. We argue that the linear representation of the genome exacerbates this complexity and an understanding of its three-dimensional structure is central to interpreting the regulatory and transcriptional architecture of the genome. Chromatin conformation capture techniques and high-resolution microscopy have afforded an emergent global view of genome structure within the nucleus. Chromosomes fold into complex, territorialized three-dimensional domains in concert with specialized subnuclear bodies that harbor concentrations of transcription and splicing machinery. The signature of these folds is retained within the layered regulatory landscapes annotated by chromatin immunoprecipitation, and we propose that genome contacts are reflected in the organization and expression of interweaved networks of overlapping coding and noncoding transcripts. This pervasive impact of genome structure favors a preeminent role for the nucleoskeleton and RNA in regulating gene expression by organizing these folds and contacts. Accordingly, we propose that the local and global three-dimensional structure of the genome provides a consistent, integrated, and intuitive framework for interpreting and understanding the regulatory and transcriptional complexity of the human genome.
\end{abstract}

It is testament to the rapid advances achieved in genome research that our conception of the human genome has changed dramatically since the publication of the first draft assembly over a decade ago (International Human Genome Sequencing Consortium 2001; Venter et al. 2001). At that time, our interpretation of the human genome was largely focused on the $\sim 1 \%$ protein-coding fraction that was interspersed across vast and largely uncharacterized intergenic noncoding regions. Aided by the advent of increasingly cheap high-throughput sequencing technologies, the genome has been rapidly annotated with detailed regulatory landmarks and transcriptional maps, revealing a complex array of overlapping and interlacing transcripts and a layered terrain of open and closed chromatin, diverse histone modifications, nucleotide modifications, and transcription factor occupancies (The ENCODE Project Consortium 2012). These overlapping layers act in concert, and in combination encompass the majority of the genome, comprising a vast landscape whose detail and rich complexity was unanticipated at the outset of the human genome project.

We are now faced with the task of interpreting this huge catalog of data in an integrated and systematic manner. Here, we argue that this interpretation can be achieved by reference to the three-dimensional folding of the genome in the nucleus. We argue that, despite its value, the current one-dimensional representation impairs an intuitive understanding of the genome, and that many current regulatory maps intrinsically reflect, indeed retain, the signatures of its higher order structure, which in turn has an overbearing role in the organization and architecture of genes and in regulating gene expression. Therefore, achieving a detailed and accurate three-dimensional representation of the genome within the nucleus has emerged as one of the major goals currently facing the field of genomic research.

\footnotetext{
'Corresponding author E-mail j.mattick@garvan.org.au

Article is online at http://www.genome.org/cgi/doi/10.1101/gr.156612.113.
}

\section{Rendering the regulatory landscape in three dimensions}

The human genome sequence exposed vast non-protein-coding regions that are replete with responsive and cell-specific regulatory elements (Thurman et al. 2012). Chromatin immunoprecipitation (ChIP) has been an invaluable technique for surveying these regions and is now widely used to identify transcription factor binding sites and chromatin modifications (Landt et al. 2012). The first genome-wide application of ChIP revealed an intricate landscape containing an unexpectedly large number of transcription factor binding sites across chromosomes $21 / 22$, often in regions distal to gene promoters (Cawley et al. 2004). However, many of these promiscuous sites are cross-linked at low levels, and similar sites fail to drive patterned reporter gene expression when systematically assayed in Drosophila (Fisher et al. 2012). Notably, many of these sites also do not contain corresponding transcription factor sequence recognition motifs, and a further subset, termed "transcription factor hotspots," exhibit simultaneous overlapping signals to numerous transcription factors (Fig. 1; Moorman et al. 2006; Roy et al. 2010; Neph et al. 2012).

Rather than bona fide sites of transcription factor binding, these promiscuous sites may reflect an artifactual enrichment resulting from proximal nonspecific cross-linking between contacts within a tightly folded genome structure. During the initial step of the ChIP-seq protocol, formaldehyde is used to cross-link occupied DNA and bound proteins, which are then immunoprecipitated by antibodies against the transcription factor of interest and digested to yield the occupied DNA for sequencing. However, the initial formaldehyde cross-linking can also nonspecifically link DNA sequences that are not bound, but rather in close spatial proximity to proteins, resulting in the parallel, collateral precipitation of juxtaposed genomic regions, potentially explaining the lack of binding nucleotide motifs within many ChIP-seq enrichments (Fig. 1A). Similarly, targeted proteins may be constituents of larger multiprotein complexes. As a result, fixation with 
A.

B. Muli:irotein Complex $\quad$ C.

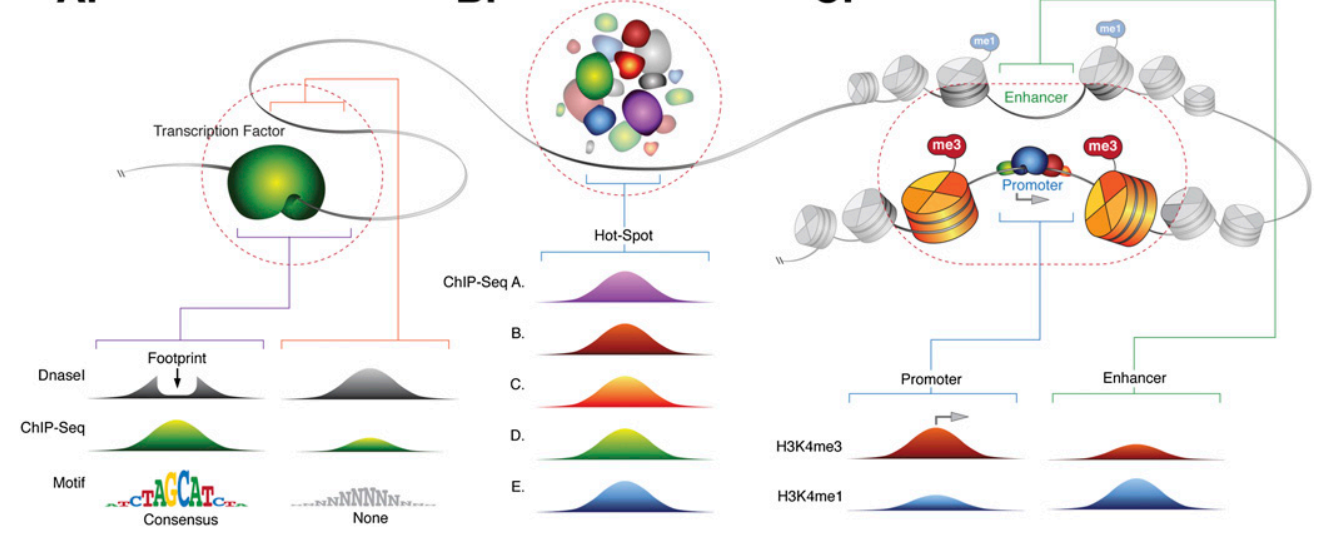

Figure 1. Examples of proximal enrichments resulting from ChIP-seq. ( $A$ ) ChIP-seq of a transcription factor (green) results in immunoprecipitation of bound DNA sequence (blue) as well as addition of DNA sequence (orange) in close proximity. Only bound sequence shows evidence of DNase I footprint and binding motif. (B) Immunoprecipitation of DNA sequence associated with large multiprotein complex results in artifactual indirect enrichments for a wide range of transcription factors. (C) Active enhancers exhibit a range of ChIP-seq enrichments as a result of a close spatial proximity to histone modification and transcription factors at promoters.

formaldehyde would immunoprecipitate the entire multiprotein complex, including any sequences bound by intermediate protein partners, resulting in a single sequence exhibiting a simultaneous enrichment for the full range of transcription factors within the complex, providing a potential interpretation for the existence of transcription factors hotspots (Fig. 1B).

While these scenarios argue for the careful interpretation of signal enrichments within ChIP-seq libraries, they also suggest that ChIP-seq libraries retain information on the three-dimensional folding of the genome and its interaction with protein structures. Indeed, this prospect forms the basis for the chromatin interaction analysis by paired-end tag sequencing (ChIA-PET) approach (Fullwood et al. 2009). ChIA-PET uses the same protocol as ChIP-seq, including the initial formaldehyde cross-linking and immunoprecipitation of targeted protein, but with the addition of a ligation step that joins coprecipitating DNA sequences before sequencing, thereby discerning those regions of the genomic sequences that copurify due to close proximity. For example, utilizing ChIA-PET shows not only the residence of the Ser2-hypophosphorylated form of RNA polymerase II at human gene promoters, but also the aggregation of these gene promoters into higher-order networks of coregulated and cotranscribed genes (Li et al. 2012). Similarly, ChIA-PET targeting H3K4me2 modifications is able to delineate interactions between promoters and distal enhancers (Chepelev et al. 2012). A comparison of ChIP-seq and matched ChIA-PET libraries reveals the extent to which numerous ChIP-seq sites may be parsimoniously resolved as alternative contacts with a common transcription factor.

Immunofluorescent microscopy using matched antibodies directly illustrates the structural information implicit within ChIPseq libraries, visualizing the subnuclear distribution of transcription factors, histone modifications, and specialized subnuclear structures (Mao et al. 2011). Transcription machinery and factors are not uniformly diffused throughout the nucleus but coalesce as distinct and discrete foci, and histone modification often form broad nuclear domains, such as the aggregation ofH3K9 methylated regions to the nucleus periphery (Bartova et al. 2008). These nuclear domains are not obvious when matched ChIP-seq libraries are aligned to the genome sequence. For example, the H3K27me3 domains and sites of polycomb complex occupancy that occur concurrently at Hox gene clusters that are dispersed across the Drosophila genome, in fact reflect the convergent localization of these distal Hox loci to common Polycomb bodies within the nucleus (Cheutin and Cavalli 2012; Sexton et al. 2012; Towbin et al. 2012). This suggests that the complexity apparent within our current linear representation of the regulatory landscape may be interpreted as the complex folding of the genome around common subnuclear structures, and a more judicious understanding of ChIP-seq libraries could be achieved with reference to threedimensional genome structure.

\section{Resolving genome folding}

Chromatin conformation capture techniques are the main current approach by which to infer three-dimensional genome structure (de Wit and de Laat 2012). These techniques also use formaldehyde-mediated cross-linking to resolve contact between genomic loci, followed by restriction enzyme digestion to extract crosslinked fragments from the chromatin. Digested termini undergo proximal ligation to form intramolecular fragments that can be used to measure the population-averaged frequency of interactions between two genomic regions (Dekker et al. 2002). This technique has been instrumental in determining significant and stable interactions between two genomic loci, such as the close physical interaction between the locus control regions and active globin genes that loop out $\sim 40-60 \mathrm{~kb}$ of intervening sequence (Tolhuis et al. 2002).

The global three-dimensional structure of the genome can be inferred from techniques, such as $\mathrm{HiC}$, that combine chromatin conformation capture with sequencing (Lieberman-Aiden et al. 2009). These studies support the adoption of a fractal-globule organization that enables the ready extrication and decondensation of the genome (Bancaud et al. 2012), as well as the organization of chromosomes into distinct radially organized subnuclear territories that were previously visualized by fluorescent in situ hybridization (Bolzer et al. 2005). These territories are further divided into gene-rich domains that extend away from the nuclear periphery and are sites of active gene expression and early replication, with the reciprocal exclusion of gene-poor regions that encompass a compact repressive late-replicating heterochromatin fraction (Simonis et al. 2006; Boyle et al. 2011; Kalhor et al. 2012).

\section{Genome Research www.genome.org}


As chromatin conformation capture has achieved higher resolution, smaller structural units, known as topologically associated domains (TADS) have been detected (Dixon et al. 2012; Nora et al. 2012). These mega-base-sized successive domains partition the genome into local, distinct, and introverted folded regions linked by intervening unfolded regions. Although contacts within these domains are dynamic, the borders of these domains are remarkably conserved during differentiation and between cell types, and seem to impose an intrinsic modular architecture to the genome. These topological domains also exhibit a close concordance to transcription factor occupancy and epigenetic domains, including large blocks of $\mathrm{H} 3 \mathrm{~K} 27 \mathrm{me} 3$ and $\mathrm{H} 3 \mathrm{~K} 9 \mathrm{me} 2$ repression (Lan et al. 2012; Shen et al. 2012). This correlation may reflect the common measurement by alternative ChIP-seq and $\mathrm{HiC}$ approaches of the genome folding around a distinct subnuclear domain, where TAD formation may delimit these segmental chromatin blocks (Nora et al. 2012).

\section{Transcription at factories}

The concept of transcription factories was first proposed in response to the clustering transcription factors as distinct and discrete foci within the nucleus (Jackson et al. 1993; Wansink et al. 1993). Transcription factories comprise large subnuclear assemblies that encompass a range of transcription factors and machinery constituents along with additional accessory proteins for RNA processing and splicing (Jackson et al. 1993; Melnik et al. 2011; Edelman and Fraser 2012). A highly specialized example of a transcription factory is provided by the nucleolus, a subnuclear organelle responsible for rDNA transcription that harbors the dedicated machinery required for the ribosomal RNA transcription, elongation, and maturation (Hernandez-Verdun et al. 2010). Over 2000 clustered rRNA copies dispersed over five chromosomes are recruited together to the nucleolus, where they are cotranscribed on the surface of the fibrillar center within the nucleolus (Nemeth and Langst 2011).

RNA polymerase I and II-dependent transcription has also been associated with similar centralized structures, with electron spectroscopic imaging visualizing a porous heterogeneous proteinrich core, with nascent transcription preceding on the surface (Eskiw et al. 2008). Emerging evidence suggests that active RNA polymerase II is commonly bound to the surface of transcription factories (Papantonis and Cook 2011). The use of fluorescent in situ hybridization to register the relative movement of gene loci and nascent transcripts during the transcription cycle shows the DNA sequence tracking through RNA polymerase II complexes that themselves remain immobile with reference to the transcription factory (Papantonis et al. 2010). However, the generality of this model is not yet resolved with, for example, microscopy of the Hsp70 loci in Drosophila polytene chromosomes providing conflicting evidence for a classical model of polymerase II recruitment (Yao et al. 2007).

The immobilization of numerous active RNA polymerase II complexes to a single specialized active compartment affords the coexpression of multiple genes (Zhou et al. 2006). Erythroid genes, located at distal sites across the genome, accrue at common transcription factories when transcriptionally active, with silent genes being excluded (Schoenfelder et al. 2010). These common compartments where the erythroid genes unite also appear specialized, harboring specific transcription factors, such as KLF1, relevant to erythroid gene expression. Similarly, the STAT transcription factor anchors coregulated genes to common compartments during the nuclear reorganization that accompanies T-cell differentiation (Hakim et al. 2013). This aggregation of multiple genes to specialized transcription factories with varying and specific regulatory components may be responsible for the correct and coordinated expression of distinct gene ontologies. Indeed, following transfection, minichromosomes cluster to different transcription factories according to the promoters and introns they contain ( $\mathrm{Xu}$ and Cook 2008).

The activation of a range of genes, including the $M y c$ and globin genes and the collinear activation of Hox genes (Osborne et al. 2004, 2007; Morey et al. 2009; Schoenfelder et al. 2010) is coincident with their nuclear relocation. The potential for this relocation to target genes to pre-assembled transcriptional compartments offers an alternative to the classical model of transcription factor recruitment. Although yet to be realized, this alternative model switches our point of reference from the linear genome being the central structure upon which transcription factors associate de novo to a three-dimensional genome that dynamically traffics genes or promoters to a central scaffold of pre-assembled transcriptional complexes (Cook 2010; Edelman and Fraser 2012). Nevertheless, such movement would be restricted within the confines of the genomes' global architecture. Live cell imaging shows that the movement of gene loci is constrained to a tight volume within the nucleus (Strickfaden et al. 2010), and ligandinduced changes to gene expression that include rapid and global transcriptional changes expand the interactions between genomic regions, but do not incur the major reorganization of chromosomes (Hakim et al. 2011).

\section{An overarching nucleoskeleton}

The local folding of enhancers to genes and genes to transcription factories promotes the topography of the genome into an overarching regulatory role. Intranuclear order, including the structure and movement of the genome, is organized by a dense, filamentous nucleoskeleton (Simon and Wilson 2011). Many proteins of the nucleoskeleton, including lamins, titin, actin, myosins, and kinesins associate with DNA, histones, chromatin modifying proteins, transcription factors, and the general transcriptional machinery (de Lanerolle and Serebryannyy 2011). Actin comprises a major component of the nucleoskeleton, of chromatin remodeling complexes, and enhances transcription by interaction with promoter and coding sequences, the RNA polymerase I-III complexes, and other RNA processing proteins (Hofmann et al. 2004). Similarly, specialized nuclear-localized myosins and kinesins are molecular motors that traffic cargo over long ranges along actin or microtubule filaments to transcriptional machinery at active genes (PesticDragovich et al. 2000; Fomproix and Percipalle 2004; Chuang et al. 2006) and, in the case of Myosin 5a, to S35 speckles that harbor splicing factors (Pranchevicius et al. 2008).

Genome folding relies on the nucleoskeleton. Large-scale chromosomal repositioning in response to serum starvation is rapid, requires energy, and is dependent on active nuclear motor complexes (Mehta et al. 2010). The nucleoskeleton may also direct the traction of genes to nuclear bodies such as transcription factories. Following induction by a transcriptional activator, migration of chromosomal loci from the nuclear periphery is perturbed in actin and myosin mutants (Chuang et al. 2006). Furthermore, the collinear induction of $\mathrm{HOXB}$ gene expression is actin dependent (Ferrai et al. 2009), and the recruitment of snRNA genes to Cajal bodies, spherical subnuclear organelles that specialize in snRNP biogenesis, requires actin and myosin (Dundr et al. 2007). Similarly, both actin and myosin play a primary role in recruiting rDNA 
clusters to the nucleolus in response to the requirements of cellular growth and differentiation (Philimonenko et al. 2004). This range of transcription factories that are dependent on actin and myosin anticipates a broad and preeminent role for the nucleoskeleton in organizing genome folding and gene expression.

\section{Complex networks of transcription}

The complexity and sheer size of the transcriptional landscape is surely one of the most significant findings to emerge since the publication of the human genome. Given that the signature of genome structure is written into the regulatory landscape, we argue it is likely that this signature is similarly written into the transcriptional landscape. Initial cDNA sequencing and tiling array projects revealed that the transcription of protein-coding genes is accompanied by noncoding RNAs (Carninci et al. 2005; Kapranov et al. 2007a). Vast swaths of noncoding DNA are transcribed into short and long noncoding RNAs that are commensurate in diversity and abundance with protein-coding genes, and have been increasingly accepted as legitimate gene products (Mercer et al. 2009). Indeed, we have still yet to reach the frontiers of the transcriptome, with targeted RNA sequencing revealing further range and complexity of noncoding transcription in intergenic regions not otherwise detected by conventional RNA sequencing (Mercer et al. 2012). The profiling of additional tissues, developmental stages, and cell types continues to expand these limits and collectively ascribe a massive depth and breadth to the human transcriptome.

Coding and noncoding genes are organized as incredibly complex networks of layered, interleaved, antisense, and overlapping transcripts (Kapranov et al. 2005). This transcriptional complexity has revealed the modular design principles of the genome, whereby a single sequence can be incorporated in numerous ways into a range of coding and noncoding, sense and antisense transcripts that overlap to form complex networks (Kapranov et al. 2007b). In response to this recurrent complexity throughout the genome, we now consider the transcript as the basic unit of the transcriptome, with the concept of a gene being revised to a higherorder definition that encompasses a functionally related group of transcripts influencing a given phenotype (Mattick 2003; Gerstein et al. 2007; Gingeras 2007; Djebali et al. 2012).

\section{The folding of transcriptional complexity}

The immobilization of RNA polymerase to nuclear structures ties the complexity of transcriptional initiation and elongation to genome structure. Recognition that splicing is a cotranscriptional process also provides an avenue by which genome structure can influence RNA processing. Therefore, we considered whether the modular design of the genome and its transcription and processing reflects and can be understood through the three-dimensional structure of the genome.

Gene expression requires the combinatorial action of alternative transcription initiation, splicing, and termination, with local chromatin loops communicating close coordination between these processes (Fig. 2; Tan-Wong et al. 2008; Moore and Proudfoot 2009). Chromatin conformation capture routinely resolves a loop that forms across the gene body, localizing gene termini to the promoter and affording contact between transcription initiation and termination processes and coassembly of associated machinery (O'Sullivan et al. 2004; O'Reilly and Greaves 2007; Singh and Hampsey 2007; Tan-Wong et al. 2008; Moore and Proudfoot 2009). This interaction also restricts the divergent transcription of ncRNAs

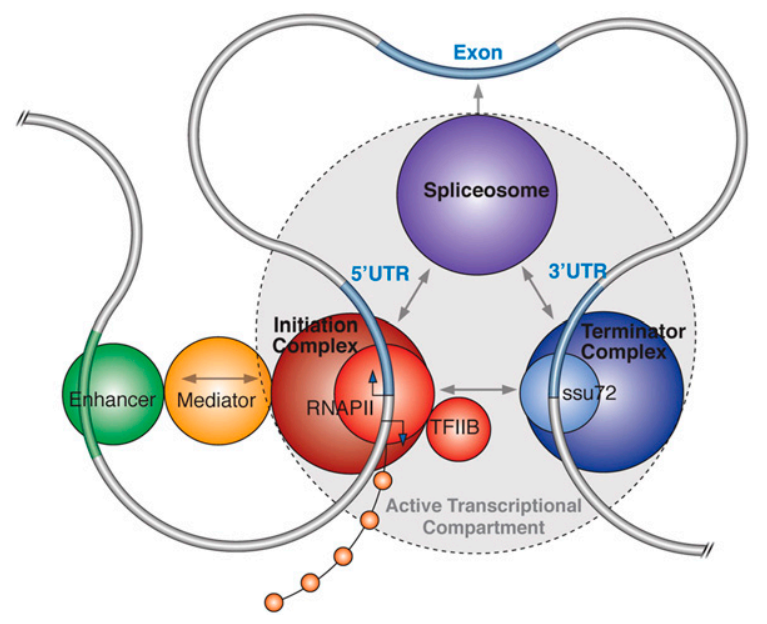

Figure 2. Formation of chromatin loops at gene loci permits coordination between processes of transcription initiation, termination, and splicing. Promoter and terminal regions of genes colocalize during transcription, forming a looped structure that enhances transcriptional directionality. Gene loop formation depends on contacts between both promoter-associated transcription factors, such as TFIIB, within the preinitiation complex and polyadenylation factors, such as Ssu72 and cleavage factor subunits, within the terminator complex. Extensive contacts between the spliceosome and the initiating and elongating polymerase II complex also facilitate cotranscriptional splicing.

and imposes directionality on the gene's promoter (Tan-Wong et al. 2012). Even further interactions between the RNA polymerase II residing at the alternative promoters used by a gene are anticipated by ChIA-PET (Li et al. 2012).

Multiple coding and noncoding transcripts are often interwoven into complex transcriptional networks (Carninci et al. 2005). Genome folding permits these interwoven RNAs to exploit a common regulatory architecture. For example, local intragenic loops permit a single promoter complex to simultaneously drive transcription of both the SPI1 gene promoter and an antisense noncoding RNA that is, counterintuitively, hosted within a downstream intron (Ebralidze et al. 2008). Further loops also bring enhancer elements to bear on the promoter complex, resulting in the assembly of a higher order structure encompassing the loci. The folding of the genome into higher ordered structures that loop out of intervening regions can prevent confusion from overlapping genes and permit compartmentalized transcription for the distinct expression of intronic-hosted genes (Fig. 3). ChIA-PET analysis targeting RNA polymerase II indicates that the genome can fold together multiple overlapping transcripts to share common regulatory features (Li et al. 2012). Such interleaved transcriptional networks, which seem complex in the linear representation of the genome, may be parsimoniously understood in the context of a three-dimensional genome.

Splicing is increasingly recognized as a cotranscriptional process, and splicing machinery and regulators comprise a major component of transcription factories (Fig. 2; Melnik et al. 2011). Like transcription initiation, a number of observations anticipate that local genome topography can be organized with relation to the gene's internal intron and exon structure, with exons being localized to cognate transcriptional machinery with intervening introns looped out (Tan-Wong et al. 2008; Moabbi et al. 2012). CTCF, better known for organizing chromatin loops and structure in conjunction with cohesin, also occupies alternative exons to mediate exon inclusion (Shukla et al. 2011; Lee and Iyer 2012). 


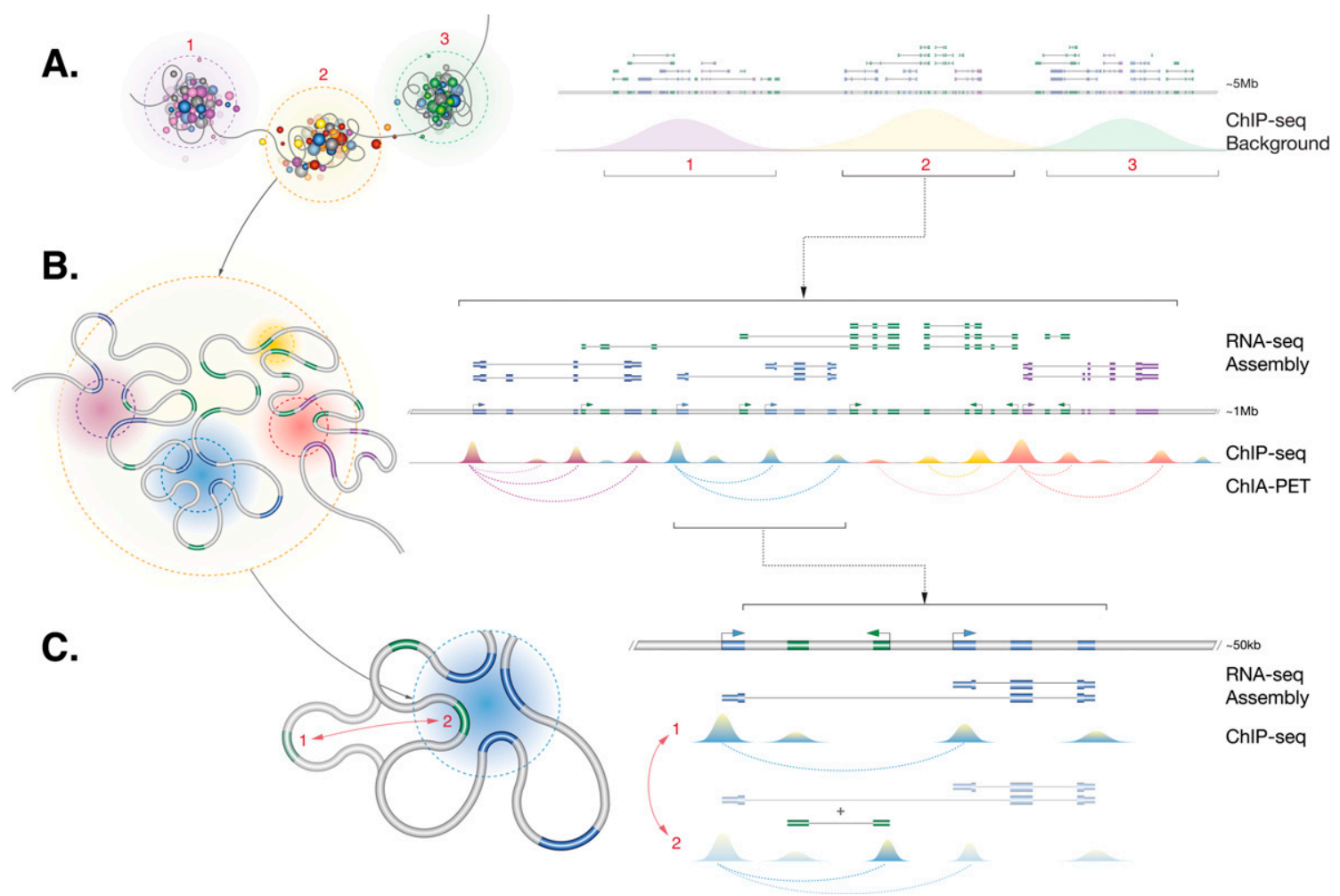

Figure 3. Three-dimensional interpretation (left) of regulatory and transcriptional complexity in one-dimensional genome representation (right). $(A)$ The genome forms large complex clusters and introspective folded clusters with specialized transcription compartments. Each of these clusters correlates to a collection of transcripts and "background" ChIP-seq enrichment. (B) Within each cluster the genome is folded to associate with subnuclear structures containing transcription factors and machinery, splicing, and other accessory proteins. These associations coregulate genes to generate interleaved complex transcriptional networks of coding (blue) and noncoding transcripts (green). Proximal cross-linking with ChIP-seq results in a complex landscape of enrichment across loci that reflect the folded genome structure. (C) Within each gene, local dynamic chromatin folding determines the association of alternative promoters and local noncoding RNAs with a shared regulatory architecture, thereby mediating coregulated gene expression.

Similarly, a range of histone modifications demarcate the intron and exon boundaries within an epigenetic landscape that is intimately linked to genome structure (Luco et al. 2011; Kornblihtt et al. 2013). Such structural and epigenetic features could help direct the spliceosome to recognize correct splice sites across often vast intronic distances.

\section{The imprint of genome structure in the transcriptional landscape}

A longer, chromosome-wide perspective shows that these complex transcriptional networks cluster to form active transcriptional foci interspersed by quiescent regions (The FANTOM Consortium 2005; Kapranov et al. 2007b). These active transcriptional foci may associate with a corresponding transcription factory, with the complex internal folding of topological domains around common regulatory cores relating to the internal detail of transcriptional networks. Collectively, these transcriptional clusters crowd within the active nuclear compartment, with distinct knots of folded chromatin that comprise topological domains demarcating boundaries between developmentally regulated transcriptional hubs, with intervening regions replete with insulators, RNA polymerase I genes, and repetitive elements (Fig. 3; Dixon et al. 2012; Sexton et al. 2012).

The folding of the genome within successive three-dimensional structures would impose constraints on the organization of encompassed genes. Transcriptional territories may partition adjacent groups of coexpressed genes in the genome (Caron et al. 2001; Spellman and Rubin 2002). Such territories could create both specialized genome property with, for example, the majority of testes-expressed genes being tightly clustered within the Drosophila genome (Boutanaev et al. 2002) and "valuable" genome property, with ubiquitously expressed genes clustering as the most gene-dense regions (Lercher et al. 2002). Clustering of coexpressed genes also inversely shapes the genomic distribution of transposable elements that space out intervening regions (Fontanillas et al. 2007).

This constraint that genome structure imposes on gene evolution is elegantly demonstrated in the collinear organization of Hox genes, critical developmental genes that evolved in the bilateral ancestor to regulate body plan. Hox genes undergo collinear activation in distinct overlapping domains according to the body axis of animal embryos (Mallo et al. 2010). This collinear transcriptional activation involves the sequential relocation of genes to an active structural compartment, while inactive Hox genes remain sequestered within a single repressive structure delimited from flanking regions (Noordermeer et al. 2011). Despite the duplication, fragmentation, reduction, and expansion of Hox loci that has occurred and correlates with major morphological changes, the collinear order of Hox gene expression and the progressive relocation of genes to active transcriptional compartments has been maintained during evolution (Lemons and McGinnis 2006). 


\section{RNA can reciprocally shape nuclear structure}

The overarching role for the structure and dynamic movement of the genome in regulating transcription may be reciprocated by RNA on genome structure. Mature RNA is stably associated with the genome, comprising a major part of chromatin where it fullfills well-established epigenetic roles (Mondal et al. 2010). The capacity for sequence-specific interactions with protein makes RNA an ideal guide and/or scaffold for the nucleation and assembly of the large regulatory structures to which the genome folds. The lncRNA, NEAT1, is required for interchromatin paraspeckle formation (Clemson et al. 2009), and the MALAT1 lncRNA sequesters serine/arginine splicing factors to nuclear speckles (Tripathi et al. 2010). Additional structures, including histone locus bodies, stress bodies, and other epigenetic bodies also require RNA for assembly (Shevtsov and Dundr 2011), anticipating a broader role for RNA in subnuclear organization. RNA can also mediate the trafficking of gene loci to subnuclear bodies, a key prediction of the alternative model of gene regulation. In response to growth signals, lncRNAs and associated chromatin modifying proteins relocate gene loci from repressive Polycomb bodies to the activating context of interchromatin granules, whereby gene expression is initiated (Yang et al. 2011).

The looping of long-range regulatory enhancers brings regulatory sequences and complexes into contact with promoters to regulate gene expression. In conjunction with this folding, enhancers themselves are often bidirectionally transcribed as nonpolyadenylated noncoding RNAs that are thought to contribute to the activation of genes targeted by the enhancer (Kim et al. 2010; Melo et al. 2012). Similarly, despite being retained at the site of transcription, the IncRNA HOTTIP recruits the WDR5/KMT2A (previously MLL) complex to impart active modifications to multiple distal sites throughout the HOXA loci via chromatin looping (Wang et al. 2011). The abundance of IncRNAs and eRNAs organized adjacent to developmental genes could similarly facilitate the tightly regulated local folding of these loci and their structural reorganization during development.

\section{A new representation of the human genome}

The linear representation of the genome enabled early efforts of gene mapping by classical genetic techniques of pedigree analysis, molecular techniques of physical mapping, and finally the assembly of the human genome sequence. Since this sequence was published, it has formed an invaluable reference to which genomewide data has been aligned and interpreted. However, the abstraction of the genome to a single dimension ignores the tight folding of the genome within the nucleus, and we are beginning to realize the limits of this linear representation and how it impairs an intuitive conception of the genome. We consider the determination and development of three-dimensional representation of the human genome to be one of the most significant challenges currently facing genome biology.

In recent years the tools and expertise have been developed that make a detailed and global description of genome topology feasible (de Wit and de Laat 2012). The integration of whole-genome and targeted chromatin conformation capture approaches, along with ChIA-PET, ChIP-seq, immunofluorescent microscopy, and fluorescent in situ hybridization are required to construct and refine such a model. However, the size, complexity and dynamism of genome structure represents a major challenge to achieving these ambitions.
In addition to its massive complexity, the genome is a highly dynamic structure. While relatively inert large-scale topodomains and nuclear structures apply constraints, the genome, particularly at a local level, is in continual and stochastic motion. It will be a major technical challenge to reproducibly resolve such dynamic features. Current chromatin conformation capture techniques provide a population-averaged depiction of genome structure, affording the identification of recurrent, stable, and significant genome interactions whereas, in contrast, high-resolution single-cell microscopy can resolve individual chromatin interactions and identify dynamic genome folding. Nevertheless, despite the dynamism, size, complexity, and plasticity of the genome that confounds any easy determination of the genome structure, laudable efforts to tackle this challenge have already been initiated (Asbury et al. 2010; Marti-Renom and Mirny 2011).

These technical challenges will also require accompanying novel visual solutions to render the dynamic genome in three dimensions. A semi-schematic depiction of the genome's internal interaction circuitry may achieve a compromise between clarity and an accurate representation of detail and complexity. This map would have to incorporate and denote dynamic regions that undergo motion and may be recast in a cell-specific manner.

Despite these challenges, achieving such a three-dimensional representation of the genome would provide an invaluable reference for biologists. Aligning and analyzing functional genomic and transcriptional data within this spatial context could provide an integrated, consistent, and judicious basis for understanding the transcriptional and regulatory complexity that has emerged as a hallmark of the human genome.

\section{Acknowledgments}

This work was supported by the Australian National Health and Medical Research Council (Australia Fellowship 631668). We also thank Professor John Stamatoyannopoulos (University of Washington) for informative and helpful discussions.

\section{References}

Asbury TM, Mitman M, Tang J, Zheng WJ. 2010. Genome3D: A viewermodel framework for integrating and visualizing multi-scale epigenomic information within a three-dimensional genome. BMC Bioinformatics 11: 444 .

Bancaud A, Lavelle C, Huet S, Ellenberg J. 2012. A fractal model for nuclear organization: Current evidence and biological implications. Nucleic Acids Res 40: 8783-8792.

Bartova E, Krejci J, Harnicarova A, Galiova G, Kozubek S. 2008. Histone modifications and nuclear architecture: A review. J Histochem Cytochem 56: 711-721.

Bolzer A, Kreth G, Solovei I, Koehler D, Saracoglu K, Fauth C, Muller S, Eils R, Cremer C, Speicher MR, et al. 2005. Three-dimensional maps of all chromosomes in human male fibroblast nuclei and prometaphase rosettes. PLoS Biol 3: e157.

Boutanaev AM, Kalmykova AI, Shevelyov YY, Nurminsky DI. 2002. Large clusters of co-expressed genes in the Drosophila genome. Nature 420: 666-669.

Boyle S, Rodesch MJ, Halvensleben HA, Jeddeloh JA, Bickmore WA. 2011. Fluorescence in situ hybridization with high-complexity repeat-free oligonucleotide probes generated by massively parallel synthesis. Chromosome Res 19: 901-909.

Caron H, van Schaik B, van der Mee M, Baas F, Riggins G, van Sluis P, Hermus MC, van Asperen R, Boon K, Voute PA, et al. 2001. The human transcriptome map: Clustering of highly expressed genes in chromosomal domains. Science 291: 1289-1292.

Cawley S, Bekiranov S, Ng HH, Kapranov P, Sekinger EA, Kampa D, Piccolboni A, Sementchenko V, Cheng J, Williams AJ, et al. 2004. Unbiased mapping of transcription factor binding sites along human chromosomes 21 and 22 points to widespread regulation of noncoding RNAs. Cell 116: 499-509. 
Chepelev I, Wei G, Wangsa D, Tang Q, Zhao K. 2012. Characterization of genome-wide enhancer-promoter interactions reveals co-expression of interacting genes and modes of higher order chromatin organization. Cell Res 22: 490-503.

Cheutin T, Cavalli G. 2012. Progressive polycomb assembly on H3K27me3 compartments generates polycomb bodies with developmentally regulated motion. PLoS Genet 8: e1002465.

Chuang CH, Carpenter AE, Fuchsova B, Johnson T, de Lanerolle P, Belmont AS. 2006. Long-range directional movement of an interphase chromosome site. Curr Biol 16: 825-831.

Clemson CM, Hutchinson JN, Sara SA, Ensminger AW, Fox AH, Chess A, Lawrence JB. 2009. An architectural role for a nuclear noncoding RNA: NEAT1 RNA is essential for the structure of paraspeckles. Mol Cell 33: 717-726.

Cook PR. 2010. A model for all genomes: The role of transcription factories. J Mol Biol 395: 1-10.

de Lanerolle P, Serebryannyy L. 2011. Nuclear actin and myosins: Life without filaments. Nat Cell Biol 13: 1282-1288.

de Wit E, de Laat W. 2012. A decade of 3C technologies: Insights into nuclear organization. Genes Dev 26: 11-24.

Dekker J, Rippe K, Dekker M, Kleckner N. 2002. Capturing chromosome conformation. Science 295: 1306-1311.

Dixon JR, Selvaraj S, Yue F, Kim A, Li Y, Shen Y, Hu M, Liu JS, Ren B. 2012. Topological domains in mammalian genomes identified by analysis of chromatin interactions. Nature 485: 376-380.

Djebali S, Davis CA, Merkel A, Dobin A, Lassmann T, Mortazavi A, Tanzer A, Lagarde J, Lin W, Schlesinger F, et al. 2012. Landscape of transcription in human cells. Nature 489: 101-108.

Dundr M, Ospina JK, Sung MH, John S, Upender M, Ried T, Hager GL, Matera AG. 2007. Actin-dependent intranuclear repositioning of an active gene locus in vivo. J Cell Biol 179: 1095-1103.

Ebralidze AK, Guibal FC, Steidl U, Zhang P, Lee S, Bartholdy B, Jorda MA, Petkova V, Rosenbauer F, Huang G, et al. 2008. PU.1 expression is modulated by the balance of functional sense and antisense RNAs regulated by a shared cis-regulatory element. Genes Dev 22: 2085-2092.

Edelman LB, Fraser P. 2012. Transcription factories: Genetic programming in three dimensions. Curr Opin Genet Dev 22: 110-114.

The ENCODE Project Consortium. 2012. An integrated encyclopedia of DNA elements in the human genome. Nature 489: 57-74.

Eskiw CH, Rapp A, Carter DR, Cook PR. 2008. RNA polymerase II activity is located on the surface of protein-rich transcription factories. J Cell Sci 121: 1999-2007.

The FANTOM Consortium. 2005. The transcriptional landscape of the mammalian genome. Science 309: 1559-1563.

Ferrai C, Naum-Ongania G, Longobardi E, Palazzolo M, Disanza A, Diaz VM, Crippa MP, Scita G, Blasi F. 2009. Induction of HoxB transcription by retinoic acid requires actin polymerization. Mol Biol Cell 20: $3543-$ 3551 .

Fisher WW, Li JJ, Hammonds AS, Brown JB, Pfeiffer BD, Weiszmann R, MacArthur S, Thomas S, Stamatoyannopoulos JA, Eisen MB, et al. 2012. DNA regions bound at low occupancy by transcription factors do not drive patterned reporter gene expression in Drosophila. Proc Natl Acad Sci 109: 21330-21335.

Fomproix N, Percipalle P. 2004. An actin-myosin complex on actively transcribing genes. Exp Cell Res 294: 140-148.

Fontanillas P, Hartl DL, Reuter M. 2007. Genome organization and gene expression shape the transposable element distribution in the Drosophila melanogaster euchromatin. PLoS Genet 3: e210.

Fullwood MJ, Liu MH, Pan YF, Liu J, Xu H, Mohamed YB, Orlov YL, Velkov S, Ho A, Mei PH, et al. 2009. An oestrogen-receptor- $\alpha$-bound human chromatin interactome. Nature 462: $58-64$.

Gerstein MB, Bruce C, Rozowsky JS, Zheng D, Du J, Korbel JO, Emanuelsson $\mathrm{O}$, Zhang ZD, Weissman S, Snyder M. 2007. What is a gene, postENCODE? History and updated definition. Genome Res 17: 669-681.

Gingeras TR. 2007. Origin of phenotypes: Genes and transcripts. Genome Res 17: $682-690$

Hakim O, Sung MH, Voss TC, Splinter E, John S, Sabo PJ, Thurman RE, Stamatoyannopoulos JA, de Laat W, Hager GL. 2011. Diverse gene reprogramming events occur in the same spatial clusters of distal regulatory elements. Genome Res 21: 697-706.

Hakim O, Sung MH, Nakayamada S, Voss TC, Baek S, Hager GL. 2013. Spatial congregation of STAT binding directs selective nuclear architecture during T-cell functional differentiation. Genome Res 23: $462-472$.

Hernandez-Verdun D, Roussel P, Thiry M, Sirri V, Lafontaine DL. 2010. The nucleolus: Structure/function relationship in RNA metabolism. Wiley Interdiscip Rev RNA 1: 415-431.

Hofmann WA, Stojiljkovic L, Fuchsova B, Vargas GM, Mavrommatis E, Philimonenko V, Kysela K, Goodrich JA, Lessard JL, Hope TJ, et al. 2004. Actin is part of pre-initiation complexes and is necessary for transcription by RNA polymerase II. Nat Cell Biol 6: 1094-1101.
International Human Genome Sequencing Consortium. 2001. Initial sequencing and analysis of the human genome. Nature 409: 860-921.

Jackson DA, Hassan AB, Errington RJ, Cook PR. 1993. Visualization of focal sites of transcription within human nuclei. EMBO J 12: 1059-1065.

Kalhor R, Tjong H, Jayathilaka N, Alber F, Chen L. 2012. Genome architectures revealed by tethered chromosome conformation capture and population-based modeling. Nat Biotechnol 30: 90-98.

Kapranov P, Drenkow J, Cheng J, Long J, Helt G, Dike S, Gingeras TR. 2005. Examples of the complex architecture of the human transcriptome revealed by RACE and high-density tiling arrays. Genome Res 15: 987-997.

Kapranov P, Cheng J, Dike S, Nix DA, Duttagupta R, Willingham AT, Stadler PF, Hertel J, Hackermuller J, Hofacker IL, et al. 2007a. RNA maps reveal new RNA classes and a possible function for pervasive transcription. Science 316: $1484-1488$.

Kapranov P, Willingham AT, Gingeras TR. 2007b. Genome-wide transcription and the implications for genomic organization. Nat Rev Genet 8: 413-423.

Kim TK, Hemberg M, Gray JM, Costa AM, Bear DM, Wu J, Harmin DA Laptewicz M, Barbara-Haley K, Kuersten S, et al. 2010. Widespread transcription at neuronal activity-regulated enhancers. Nature $\mathbf{4 6 5}$ $182-187$.

Kornblihtt AR, Schor IE, Allo M, Dujardin G, Petrillo E, Munoz MJ. 2013. Alternative splicing: A pivotal step between eukaryotic transcription and translation. Nat Rev Mol Cell Biol 14: 153-165.

Lan X, Witt H, Katsumura K, Ye Z, Wang Q, Bresnick EH, Farnham PJ, Jin VX. 2012. Integration of Hi-C and ChIP-seq data reveals distinct types of chromatin linkages. Nucleic Acids Res 40: 7690-7704.

Landt SG, Marinov GK, Kundaje A, Kheradpour P, Pauli F, Batzoglou S, Bernstein BE, Bickel P, Brown JB, Cayting P, et al. 2012. ChIP-seq guidelines and practices of the ENCODE and modENCODE consortia. Genome Res 22: 1813-1831.

Lee BK, Iyer VR. 2012. Genome-wide studies of CCCTC-binding factor (CTCF) and cohesin provide insight into chromatin structure and regulation. J Biol Chem 287: 30906-30913.

Lemons D, McGinnis W. 2006. Genomic evolution of Hox gene clusters. Science 313: 1918-1922.

Lercher MJ, Urrutia AO, Hurst LD. 2002. Clustering of housekeeping genes provides a unified model of gene order in the human genome. Nat Genet 31: 180-183.

Li G, Ruan X, Auerbach RK, Sandhu KS, Zheng M, Wang P, Poh HM, Goh Y, Lim J, Zhang J, et al. 2012. Extensive promoter-centered chromatin interactions provide a topological basis for transcription regulation. Cell 148: $84-98$.

Lieberman-Aiden E, van Berkum NL, Williams L, Imakaev M, Ragoczy T, Telling A, Amit I, Lajoie BR, Sabo PJ, Dorschner MO, et al. 2009. Comprehensive mapping of long-range interactions reveals folding principles of the human genome. Science 326: 289-293.

Luco RF, Allo M, Schor IE, Kornblihtt AR, Misteli T. 2011. Epigenetics in alternative pre-mRNA splicing. Cell 144: 16-26.

Mallo M, Wellik DM, Deschamps J. 2010. Hox genes and regional patterning of the vertebrate body plan. Dev Biol 344: 7-15.

Mao YS, Zhang B, Spector DL. 2011. Biogenesis and function of nuclear bodies. Trends Genet 27: 295-306.

Marti-Renom MA, Mirny LA. 2011. Bridging the resolution gap in structural modeling of 3D genome organization. PLoS Comput Biol 7: e1002125.

Mattick JS. 2003. Challenging the dogma: The hidden layer of non-proteincoding RNAs in complex organisms. BioEssays 25: 930-939.

Mehta IS, Amira M, Harvey AJ, Bridger JM. 2010. Rapid chromosome territory relocation by nuclear motor activity in response to serum removal in primary human fibroblasts. Genome Biol 11: R5.

Melnik S, Deng B, Papantonis A, Baboo S, Carr IM, Cook PR. 2011. The proteomes of transcription factories containing RNA polymerases I, II or III. Nat Methods 8: 963-968.

Melo CA, Drost J, Wijchers PJ, van de Werken H, de Wit E, Vrielink JA, Elkon R, Melo SA, Leveille N, Kalluri R, et al. 2012. eRNAs are required for p53dependent enhancer activity and gene transcription. Mol Cell 49: 524525.

Mercer TR, Dinger ME, Mattick JS. 2009. Long non-coding RNAs: Insights into functions. Nat Rev Genet 10: $155-159$.

Mercer TR, Gerhardt DJ, Dinger ME, Crawford J, Trapnell C, Jeddeloh JA Mattick JS, Rinn JL. 2012. Targeted RNA sequencing reveals the deep complexity of the human transcriptome. Nat Biotechnol 30: 99-104.

Moabbi AM, Agarwal N, El Kaderi B, Ansari A. 2012. Role for gene looping in intron-mediated enhancement of transcription. Proc Natl Acad Sci 109: 8505-8510.

Mondal T, Rasmussen M, Pandey GK, Isaksson A, Kanduri C. 2010. Characterization of the RNA content of chromatin. Genome Res 20: 899_ 907.

Moore MJ, Proudfoot NJ. 2009. Pre-mRNA processing reaches back to transcription and ahead to translation. Cell 136: $688-700$. 
Moorman C, Sun LV, Wang J, de Wit E, Talhout W, Ward LD, Greil F, Lu XJ, White KP, Bussemaker HJ, et al. 2006. Hotspots of transcription factor colocalization in the genome of Drosophila melanogaster. Proc Natl Acad Sci 103: 12027-12032.

Morey C, Kress C, Bickmore WA. 2009. Lack of bystander activation shows that localization exterior to chromosome territories is not sufficient to up-regulate gene expression. Genome Res 19: 1184-1194.

Nemeth A, Langst G. 2011. Genome organization in and around the nucleolus. Trends Genet 27: 149-156.

Neph S, Vierstra J, Stergachis AB, Reynolds AP, Haugen E, Vernot B, Thurman RE, John S, Sandstrom R, Johnson AK, et al. 2012. An expansive human regulatory lexicon encoded in transcription factor footprints. Nature 489: 83-90.

Noordermeer D, Leleu M, Splinter E, Rougemont J, De Laat W, Duboule D. 2011. The dynamic architecture of Hox gene clusters. Science 334: 222-225.

Nora EP, Lajoie BR, Schulz EG, Giorgetti L, Okamoto I, Servant N, Piolot T, van Berkum NL, Meisig J, Sedat J, et al. 2012. Spatial partitioning of the regulatory landscape of the X-inactivation centre. Nature 485: 381-385.

O'Reilly D, Greaves DR. 2007. Cell-type-specific expression of the human CD68 gene is associated with changes in Pol II phosphorylation and short-range intrachromosomal gene looping. Genomics 90: 407-415.

O'Sullivan JM, Tan-Wong SM, Morillon A, Lee B, Coles J, Mellor J, Proudfoot NJ. 2004. Gene loops juxtapose promoters and terminators in yeast. Nat Genet 36: 1014-1018.

Osborne CS, Chakalova L, Brown KE, Carter D, Horton A, Debrand E, Goyenechea B, Mitchell JA, Lopes S, Reik W, et al. 2004. Active genes dynamically colocalize to shared sites of ongoing transcription. Nat Genet 36: 1065-1071.

Osborne CS, Chakalova L, Mitchell JA, Horton A, Wood AL, Bolland DJ, Corcoran AE, Fraser P. 2007. Myc dynamically and preferentially relocates to a transcription factory occupied by Igh. PLoS Biol 5: e192.

Papantonis A, Cook PR. 2011. Fixing the model for transcription: The DNA moves, not the polymerase. Transcription 2: 41-44.

Papantonis A, Larkin JD, Wada Y, Ohta Y, Ihara S, Kodama T, Cook PR. 2010 Active RNA polymerases: Mobile or immobile molecular machines? PLoS Biol 8: e1000419.

Pestic-Dragovich L, Stojiljkovic L, Philimonenko AA, Nowak G, Ke Y, Settlage RE, Shabanowitz J, Hunt DF, Hozak P, de Lanerolle P. 2000. A myosin I isoform in the nucleus. Science 290: 337-341.

Philimonenko VV, Zhao J, Iben S, Dingova H, Kysela K, Kahle M, Zentgraf H, Hofmann WA, de Lanerolle P, Hozak P, et al. 2004. Nuclear actin and myosin I are required for RNA polymerase I transcription. Nat Cell Biol 6: 1165-1172.

Pranchevicius MC, Baqui MM, Ishikawa-Ankerhold HC, Lourenco EV, Leao RM, Banzi SR, dos Santos CT, Roque-Barreira MC, Espreafico EM, Larson RE. 2008. Myosin Va phosphorylated on $\operatorname{Ser}^{1650}$ is found in nuclear speckles and redistributes to nucleoli upon inhibition of transcription. Cell Motil Cytoskeleton 65: 441-456.

Roy S, Ernst J, Kharchenko PV, Kheradpour P, Negre N, Eaton ML, Landolin JM, Bristow CA, Ma L, Lin MF, et al. 2010. Identification of functional elements and regulatory circuits by Drosophila modENCODE. Science 330: 1787-1797.

Schoenfelder S, Sexton T, Chakalova L, Cope NF, Horton A, Andrews S, Kurukuti S, Mitchell JA, Umlauf D, Dimitrova DS, et al. 2010. Preferential associations between co-regulated genes reveal a transcriptional interactome in erythroid cells. Nat Genet 42: 53-61.

Sexton T, Yaffe E, Kenigsberg E, Bantignies F, Leblanc B, Hoichman M, Parrinello H, Tanay A, Cavalli G. 2012. Three-dimensional folding and functional organization principles of the Drosophila genome. Cell 148: $458-472$.

Shen Y, Yue F, McCleary DF, Ye Z, Edsall L, Kuan S, Wagner U, Dixon J, Lee L, Lobanenkov VV, et al. 2012. A map of the cis-regulatory sequences in the mouse genome. Nature 488: 116-120.
Shevtsov SP, Dundr M. 2011. Nucleation of nuclear bodies by RNA. Nat Cell Biol 13: 167-173.

Shukla S, Kavak E, Gregory M, Imashimizu M, Shutinoski B, Kashlev M, Oberdoerffer P, Sandberg R, Oberdoerffer S. 2011. CTCF-promoted RNA polymerase II pausing links DNA methylation to splicing. Nature 479: 74-79.

Simon DN, Wilson KL. 2011. The nucleoskeleton as a genome-associated dynamic 'network of networks'. Nat Rev Mol Cell Biol 12: 695-708.

Simonis M, Klous P, Splinter E, Moshkin Y, Willemsen R, de Wit E, van Steensel B, de Laat W. 2006. Nuclear organization of active and inactive chromatin domains uncovered by chromosome conformation captureon-chip (4C). Nat Genet 38: 1348-1354.

Singh BN, Hampsey M. 2007. A transcription-independent role for TFIIB in gene looping. Mol Cell 27: 806-816.

Spellman PT, Rubin GM. 2002. Evidence for large domains of similarly expressed genes in the Drosophila genome. J Biol 1: 5 .

Strickfaden H, Zunhammer A, van Koningsbruggen S, Kohler D, Cremer T. 2010. 4D chromatin dynamics in cycling cells: Theodor Boveri's hypotheses revisited. Nucleus 1: 284-297.

Tan-Wong SM, French JD, Proudfoot NJ, Brown MA. 2008. Dynamic interactions between the promoter and terminator regions of the mammalian BRCA1 gene. Proc Natl Acad Sci 105: 5160-5165.

Tan-Wong SM, Zaugg JB, Camblong J, Xu Z, Zhang DW, Mischo HE, Ansari AZ, Luscombe NM, Steinmetz LM, Proudfoot NJ. 2012. Gene loops enhance transcriptional directionality. Science 338: 671-675.

Thurman RE, Rynes E, Humbert R, Vierstra J, Maurano MT, Haugen E, Sheffield NC, Stergachis AB, Wang H, Vernot B, et al. 2012. The accessible chromatin landscape of the human genome. Nature 489: 75-82.

Tolhuis B, Palstra RJ, Splinter E, Grosveld F, de Laat W. 2002. Looping and interaction between hypersensitive sites in the active $\beta$-globin locus Mol Cell 10: 1453-1465.

Towbin BD, Gonzalez-Aguilera C, Sack R, Gaidatzis D, Kalck V, Meister P, Askjaer P, Gasser SM. 2012. Step-wise methylation of histone H3K9 positions heterochromatin at the nuclear periphery. Cell 150: 934-947.

Tripathi V, Ellis JD, Shen Z, Song DY, Pan Q, Watt AT, Freier SM, Bennett CF, Sharma A, Bubulya PA, et al. 2010. The nuclear-retained noncoding RNA MALAT1 regulates alternative splicing by modulating SR splicing factor phosphorylation. Mol Cell 39: 925-938.

Venter JC, Adams MD, Myers EW, Li PW, Mural RJ, Sutton GG, Smith HO, Yandell M, Evans CA, Holt RA, et al. 2001. The sequence of the human genome. Science 291: 1304-1351.

Wang KC, Yang YW, Liu B, Sanyal A, Corces-Zimmerman R, Chen Y, Lajoie BR, Protacio A, Flynn RA, Gupta RA, et al. 2011. A long noncoding RNA maintains active chromatin to coordinate homeotic gene expression. Nature 472: $120-124$.

Wansink DG, Schul W, van der Kraan I, van Steensel B, van Driel R, de Jong L. 1993. Fluorescent labeling of nascent RNA reveals transcription by RNA polymerase II in domains scattered throughout the nucleus. J Cell Biol 122: 283-293.

Xu M, Cook PR. 2008. Similar active genes cluster in specialized transcription factories. J Cell Biol 181: 615-623.

Yang L, Lin C, Liu W, Zhang J, Ohgi KA, Grinstein JD, Dorrestein PC, Rosenfeld MG. 2011. ncRNA- and Pc2 methylation-dependent gene relocation between nuclear structures mediates gene activation programs. Cell 147: 773-788.

Yao J, Ardehali MB, Fecko CJ, Webb WW, Lis JT. 2007. Intranuclear distribution and local dynamics of RNA polymerase II during transcription activation. Mol Cell 28: 978-990.

Zhou GL, Xin L, Song W, Di LJ, Liu G, Wu XS, Liu DP, Liang CC. 2006. Active chromatin hub of the mouse $\alpha$-globin locus forms in a transcription factory of clustered housekeeping genes. Mol Cell Biol 26: $5096-5105$. 


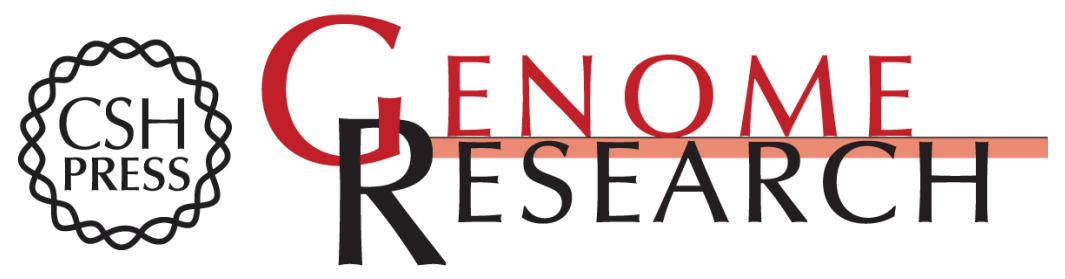

\section{Understanding the regulatory and transcriptional complexity of the genome through structure}

Tim R. Mercer and John S. Mattick

Genome Res. 2013 23: 1081-1088

Access the most recent version at doi:10.1101/gr.156612.113

References This article cites 102 articles, 32 of which can be accessed free at:

http://genome.cshlp.org/content/23/7/1081.full.html\#ref-list-1

Creative This article is distributed exclusively by Cold Spring Harbor Laboratory Press for the Commons License first six months after the full-issue publication date (see

http://genome.cshlp.org/site/misc/terms.xhtml). After six months, it is available under a Creative Commons License (Attribution-NonCommercial 3.0 Unported), as described at http://creativecommons.org/licenses/by-nc/3.0/.

Email Alerting

Receive free email alerts when new articles cite this article - sign up in the box at the Service top right corner of the article or click here.

\section{Affordable, Accurate Sequencing.}

To subscribe to Genome Research go to:

https://genome.cshlp.org/subscriptions 